\title{
Avaliações Fisiológicas e Bioquímicas de Plantas de Aguapé (Eichhornia crassipes) CULTIVADAS COM NÍVEIS EXCESSIVOS DE NUTRIENTES ${ }^{1}$
}

\author{
Physiological and Biochemical Evaluations of Water Hyacinth (Eichhornia crassipes), \\ Cultivated with Excessive Nutrient Levels
}
ALVES, E. ${ }^{2}$, CARDOSO, L.R. ${ }^{2}$, SCAVRONI, J. ${ }^{3}$, L.R., FERREIRA, L.C. ${ }^{3}$, BOARO, C.S.F. ${ }^{4}{ }^{\text {e }}$ CATANEO, A.C. ${ }^{5}$

\begin{abstract}
RESUMO - Plantas de aguapé foram cultivadas em solução nutritiva de Hoagland \& Arnon n.2, cujo aumento dos níveis de $\mathrm{N}, \mathrm{P}$ e $\mathrm{Cu}$ estabeleceu as diferenças entre os tratamentos. Utilizou-se o delineamento experimental inteiramente casualizado, com quatro repetições. As variáveis fisiológicas avaliadas foram área foliar, peso de matéria seca e taxa de crescimento absoluto, taxa de crescimento relativo, taxa assimilatória líquida, razão de área foliar, peso específico de folha, área foliar específica. Foram determinados também os teores de açúcares totais e redutores e de aminoácidos totais e a atividade das enzimas glutationa S-transferase e superóxido dismutase. Os extratos enzimáticos foram obtidos da matéria fresca da parte aérea das plantas. Após a coleta, foram determinados os pesos de material seco de raízes, pecíolos e folhas, que foram utilizados para a determinação de açúcares solúveis totais e redutores e de aminoácidos. O excesso de nitrogênio causou aumento de açúcares nas folhas e de aminoácidos nas raízes. Já o tratamento com excesso de fósforo levou ao aumento de açúcares nas raízes. Os resultados apresentados sugerem que, entre os nutrientes em excesso avaliados, o cobre $\left(0,12 \mathrm{mg} \mathrm{L}^{-1}\right)$ foi o maior indutor da atividade da GST e SOD, sugerindo que este elemento induziu estresse nas plantas de aguapé.
\end{abstract}

Palavras-chave: metal pesado, superóxido dismutase, glutationa S-transferase, análise de crescimento.

\begin{abstract}
Water hyacinth plants were cultivated in a Hoagland \&. Arnon n.2 nutrient solution with increased $\mathrm{N}, \mathrm{P}$ and $\mathrm{Cu}$ levels establishing the differences among the treatments. The experimental design was completely randomized, with four replicates. Physiological evaluations included leaf area, dry matter and growth analysis parameters (absolute growth rate, relative growth rate, net assimilatory rate, leaf area ratio, specific leaf weight, specific leaf area). Biochemistry evaluations were total and reducing sugars, total amino acids and activity of the antioxidant enzymes (glutathione S-transferase and superoxide dismutase). The enzyme extract was obtained from fresh matter of the aerial part of the plants. Root and leaf dry material was used to determine total and reducing sugars, and amino acids. Nitrogen supplementation caused increased levels of sugars in the leaves and of amino acids in the roots. The treatment with excess phosphorus caused increased levels of sugars in the roots. The results suggest that copper (0.12 $\left.\mathrm{mg} \mathrm{L}^{-1}\right)$ increased the activity of GST and SOD, inducing stress in the water hyacinth plants.
\end{abstract}

Key words: heavy metal, superoxide dismutase, glutathione S-transferase, and plant growth analysis.

\footnotetext{
Recebido para publicação em 16.12.2002 e na forma revisada em 28.5.2003.

2 Alunos do Programa de Pós-Graduação em Agronomia, Departamento de Produção Vegetal - setor Agricultura da Faculdade de Ciências Agronômicas - FCA-UNESP, Caixa Postal 237, 18603-970 Botucatu-SP, <eacorrea@ fca.unesp.br>; ${ }^{3}$ Alunos do Programa de Pós-Graduação em Botânica, Departamento de Botânica IB-UNESP, Botucatu-SP; ${ }^{4}$ Professor Adjunto, Departamento de Botânica - Instituto de Biociências, UNESP - Botucatu-SP. ${ }^{5}$ Professor Adjunto, Departamento de Química e Bioquímica Instituto de Biociências, UNESP - Botucatu-SP.
} 


\section{INTRODUÇÃO}

Eichhornia crassipes (aguapé) é uma planta daninha aquática emersa capaz de aumentar sua massa verde em $15 \%$ ao dia, dobrando-a a cada seis ou sete dias, acumulando $800 \mathrm{~kg}$ por hectare por dia. Quando em condições ótimas, produz até 480 toneladas de massa verde por hectare em um ano, com um incremento de volume de $4,8 \%$ ao dia. Um lago coberto por aguapés perde de duas a oito vezes mais água por evapotranspiração do que se estivesse com a superfície livre (Marcondes \& Tanaka, 1997).

Moraes (1999) afirma que a comunidade de macrófitas aquáticas tem atraído o interesse de diversos pesquisadores, particularmente devido à sua capacidade de retenção de nutrientes. O autor afirma ainda que a oferta constante de nutrientes resulta também na proliferação das macrófitas, que encontram em reservatórios condições propícias para crescimento descontrolado.

Neves et al. (2002) declaram que o crescente desenvolvimento tecnológico promove sérios desequilíbrios nos ambientes aquáticos. A retirada da proteção e da competição proporcionada pelas matas ciliares, a erosão de solos agrícolas e o despejo de resíduos industriais e urbanos que se acumulam alteram o equilíbrio físico-químico desses ambientes.

Além disso, a proliferação desordenada do aguapé é extremamente prejudicial ao funcionamento operacional de barragens, à navegação e à recreação, além de consistir em sítio reprodutivo para organismos vetores de doenças. Ao receber uma descarga de resíduos, os organismos aquáticos iniciam o processo de autodepuração e transformam o material biodegradável em nutrientes, promovendo freqüentemente a eutrofização dos ambientes aquáticos (Neves et al., 2002).

Segundo Corrêa et al. (2002), o crescimento do aguapé é diretamente proporcional ao fornecimento de níveis baixos ou moderados de nutrientes. Quando os nutrientes encontram-se em concentrações elevadas, não ocasionam aumento do crescimento da planta, mas acarretam sua assimilação luxuriante, sendo esse fato preferível à intoxicação da vida aquática. Com o crescente processo de eutrofização, os vegetais aquáticos, desde algas até macrófitas, podem se tornar um problema, em razão do crescimento rápido e desordenado, decorrente do desequilíbrio do ambiente. O excesso de nutrientes tem se tornado preocupante, devido à utilização de grande variedade de elementos.

Corrêa et al. (2002) afirma que o desenvolvimento adequado e a proliferação de macrófitas dependem de nutrientes como $\mathrm{C}, \mathrm{N}, \mathrm{P}$, $\mathrm{S}, \mathrm{K}, \mathrm{Ca}, \mathrm{Mg}, \mathrm{Mo}, \mathrm{Mn}$ e $\mathrm{Cu}$, que, em baixas concentrações, são essenciais para os processos metabólicos normais. O fósforo e o nitrogênio são os nutrientes mais exigidos pelas plantas de aguapé; quando os teores desses elementos encontram-se elevados, tornam-se potencialmente citotóxicos, atuando como poluentes ambientais.

Lopes-Ferreira (1995) constatou o efeito depurador de macrófitas no tratamento de esgotos sanitários, reduzindo a carga de nutrientes, de coliformes e a demanda bioquímica de oxigênio (DBO), por meio da adsorção de material orgânico particulado e dissolvido pelas raízes. O autor afirma que a alta concentração de nutrientes satura as plantas, podendo ocorrer degeneração no metabolismo, embora a assimilação luxuriante possa ser limitada por algum mecanismo de defesa.

Rama Devi \& Prasad (1985) citam que o cobre, apesar de em concentrações inadequadas ser considerado um poluente ambiental, é um nutriente essencial, participando como componente de várias enzimas e, principalmente, catalisando reações de redução no transporte de elétrons. Além disso, exerce funções na síntese de proteínas, no metabolismo de carboidratos e na fixação simbiótica de nitrogênio (Marschner, 1995; Nelson \& Cox, 2000).

O cobre é potencialmente gerador de espécies reativas de oxigênio, como, por exemplo, radicais superóxido $\left(\mathrm{O}_{2}{ }^{*-}\right)$ e hidroxila ( $\left.\mathrm{HO}^{*}\right)$ e peróxido de hidrogênio $\left(\mathrm{H}_{2} \mathrm{O}_{2}\right)$. Conseqüentemente, quando em excesso, este metal pode causar danos severos, adicionando grupos sulfidrila às proteínas e induzindo a peroxidação de lipídios das membranas celulares (Aust et al., 1989; De Vos et al., 1992).

Em razão da constante exposição a inúmeros compostos químicos externos e potencialmente tóxicos (compostos xenobióticos), as 
plantas desenvolveram processos bioquímicos para combatê-los (Sies, 1993; Coleman et al., 1997). Enzimas como a superóxido dismutase (SODs, EC 1.15.1.1) e a glutationa S-transferase (GST, EC 2.5.1.18) desempenham ações relevantes no metabolismo celular normal, na desintoxicação de ampla variedade de compostos xenobióticos e na defesa contra substâncias oxidantes. As SODs são metaloenzimas que ocorrem em três formas moleculares que contêm os metais $\mathrm{Mn}, \mathrm{Fe}$ ou $\mathrm{CuZn}$ como grupos prostéticos, que catalisam a dismutação de $\mathrm{O}_{2}^{*-}$ a $\mathrm{H}_{2} \mathrm{O}_{2}$ e $_{2}$ (Fridovich, 1986). Já as GSTs são consideradas enzimas de desintoxicação, pois catalisam a conjugação de glutationa a uma variedade de substratos citotóxicos, sendo induzidos por metais pesados (MacDonald et al., 1991; Bilang et al., 1993). Portanto, a atividade destas enzimas é de importância significativa para a sobrevivência de organismos submetidos a estresses ambientais.

Com base no exposto, o presente estudo teve como objetivo avaliar o comportamento fisiológico, a atividade de enzimas antioxidantes (GST e SOD) e os teores de carboidratos e aminoácidos em plantas de aguapé submetidas a excesso de nitrogênio, fósforo e cobre.

\section{MATERIAL E MÉTODOS}

O experimento foi conduzido em casa de vegetação no Departamento de Botânica do Instituto de Biociências - UNESP, campus de Botucatu (SP). As avaliações bioquímicas foram realizadas no Laboratório de Bioquímica de Xenobióticos desta mesma unidade.

As plantas de aguapé foram coletadas de um lago situado na Fazenda Experimental Lageado, Botucatu-SP, selecionadas quanto à uniformidade de tamanho, lavadas e mantidas por 48 horas em água desmineralizada. Após este período, foram transferidas para recipientes de polietileno contendo três litros de solução nutritiva no 2 de Hoagland \& Arnon (1950), cujo aumento dos níveis de $\mathrm{N}, \mathrm{P}$ e $\mathrm{Cu}$ estabeleceu as diferenças entre os tratamentos. Esses tratamentos foram assim designados: TC (tratamento controle), no qual foi utilizada a solução nutritiva completa; TN, em que a solução continha o dobro da concentração de $\mathrm{N}$ - igual a $420 \mathrm{mg} \mathrm{L}^{-1}$; TP, em que a solução continha o dobro da concentração de $\mathrm{P}$ - igual a $64 \mathrm{mg} \mathrm{L}^{-1}$; TCu-I, em que a solução continha o dobro da concentração de $\mathrm{Cu}$ - igual a $0,16 \mathrm{mg} \mathrm{L}^{-1}$; e TCu-II, em que a solução continha $50 \%$ da concentração de $\mathrm{Cu}$ - igual a $0,12 \mathrm{mg} \mathrm{L}^{-1}$.

O delineamento experimental foi o inteiramente casualizado, com quatro repetições. As plantas foram coletadas em duas épocas, aos 28 e 45 dias de cultivo, sendo separadas em raízes, pecíolos e folhas. Em seguida, determinou-se a área foliar, com posterior secagem dos diferentes órgãos em estufa de circulação forçada de ar a $60{ }^{\circ} \mathrm{C}$. O material seco e moído de folhas e raízes foi utilizado para a determinação dos teores de açúcares solúveis totais e redutores e de aminoácidos totais e para a determinação das variáveis análise de crescimento, taxa de crescimento absoluto (TCA), taxa de crescimento relativo (TCR), taxa assimilatória líquida (TAL), razão de área foliar (RAF), peso específico de folha (PEF), razão de massa foliar (RMF) e área foliar específica (AFE), de acordo com as especificações de Benincasa (1988). Os açúcares solúveis totais e redutores foram determinados de acordo com o método de Dubois et al. (1956) e Nelson (1944), respectivamente. Os aminoácidos totais foram determinados segundo o método proposto por Kabat \& Mayer (1967). As amostras para determinações enzimáticas foram obtidas a partir de extratos da matéria fresca da parte aérea das plantas nas duas épocas de coleta. Estas determinações seguiram o método proposto por Wu (1996) para GST e o proposto por Giannopolitis \& Ries (1977) para SOD. O conteúdo de proteína solúvel total nos extratos enzimáticos foi determinado de acordo com o método de Lowry et al. (1951). Os resultados foram submetidos à análise de variância e as médias comparadas pelo teste de Tukey a $5 \%$ de probabilidade.

\section{RESULTADOS E DISCUSSÃO}

As plantas submetidas aos tratamentos TN e TCu II, em relação à testemunha, reduziram em 32,0 e $15,0 \%$, respectivamente, sua velocidade de crescimento (TCA) e em 9,2 e 5,6\%, respectivamente, a produção de massa seca (TCR). Já aquelas submetidas aos tratamentos TP e TCu I apresentaram incremento de 11,3 e $11,5 \%$, respectivamente, na TCA e de 2,0 e $0,5 \%$, respectivamente, na TCR (Figura 1a). 

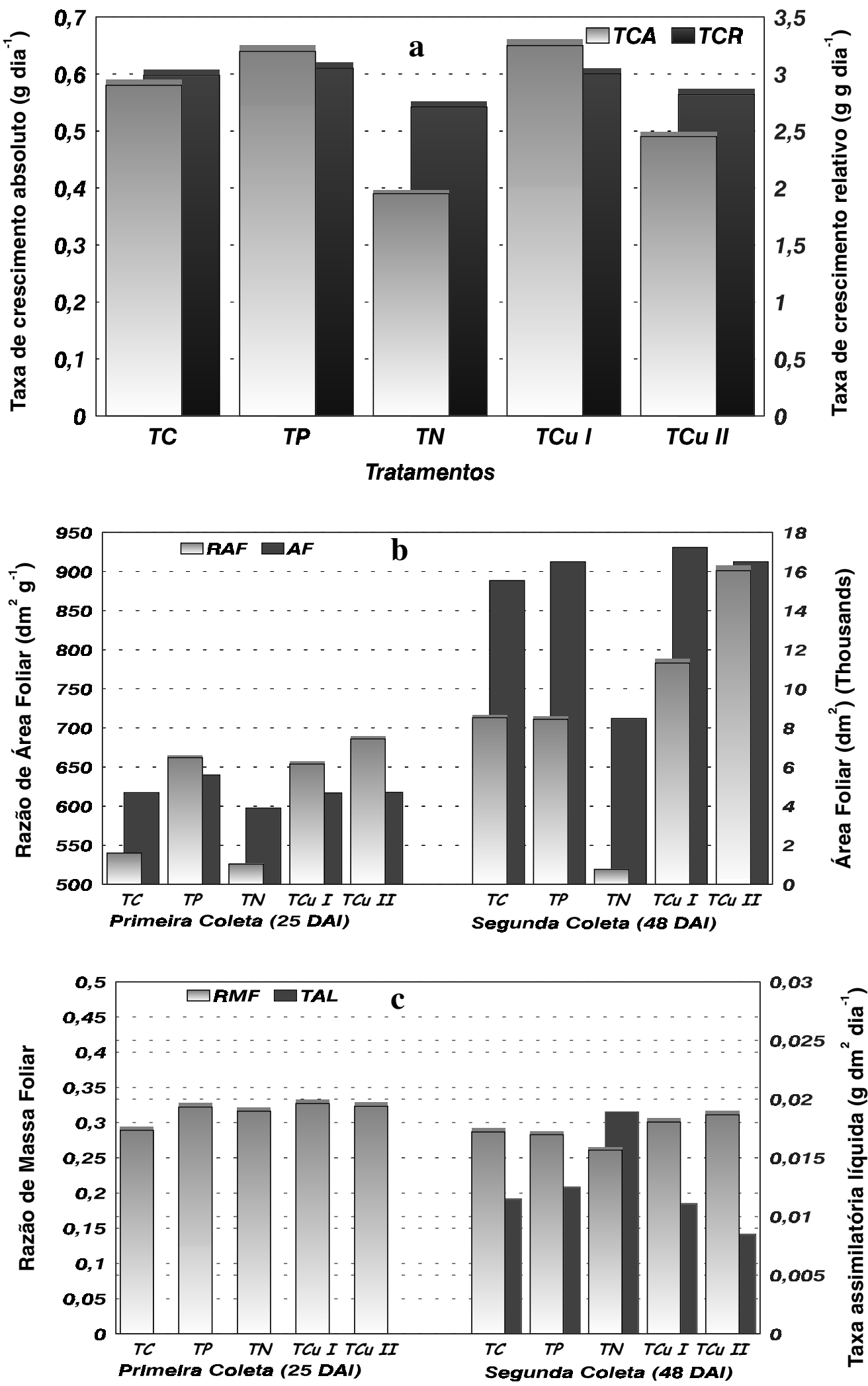

Figura 1 - Variáveis da análise de crescimento em plantas de aguapé submetidas a tratamentos com excesso de nutrientes. TCA e TCR (a); RAF e AF (b); RMF e TAL (c). Botucatu-SP, 2002. 
A área foliar e a área foliar útil para a fotossintese (RAF) tiveram o mesmo comportamento nas duas épocas de coleta (Figura 1b), com diminuições somente nas plantas cultivadas no tratamento TN, que apresentaram reduções de $45,4 \%$ para área foliar e $27,2 \%$ para $\mathrm{RAF}$ aos 48 dias após a transferência para a solução nutritiva (DAT). No entanto, as plantas submetidas ao tratamento TN apresentaram eficiência fotossintética (TAL) $64,8 \%$ superior à da testemunha (Figura 1c).

A matéria seca das plantas não foi influenciada pelos tratamentos em nenhuma das épocas de coleta, porém observou-se maior acúmulo de matéria seca nos pecíolos (Tabela 1). O tratamento TP proporcionou incremento de área foliar de $18,8 \%$ aos 25 DAT e de $6,2 \%$ aos 48 DAT. Os tratamentos com excesso de cobre (TCu I e TCu II) apresentaram maiores valores de área foliar aos 48 DAT (Tabela 1).

Os teores de açúcares totais e redutores e de aminoácidos de folhas e raízes de plantas de aguapé, nas duas épocas de coleta, não diferiram entre as plantas submetidas aos diferentes tratamentos (Tabela 2). Entretanto, na primeira coleta, realizada aos 25 DAT, observou-se que nas folhas das plantas submetidas ao tratamento com excesso de $\mathrm{N}$ ocorreu incremento de 59,1 e 57,4\%, respectivamente, de açúcares solúveis redutores e totais, em comparação com a testemunha. Incrementos de $73,2 \%$ de açúcares redutores e de $72,8 \%$ de açúcares totais foram observados nas raizes das plantas submetidas ao excesso de $\mathrm{P}$, em relação à testemunha. O excesso de $\mathrm{N}$ acarretou aumento de aminoácidos totais nas raízes das plantas de aguapé nas duas épocas analisadas.

A assimilação de $\mathrm{N}$ é um processo vital que controla o crescimento e o desenvolvimento da planta. O nitrogênio inorgânico é assimilado em aminoácidos, que servem como importantes armazenadores de nitrogênio em plantas (Lam et al., 1996; Buchanan et al., 2001). Pode-se verificar uma correlação direta de suprimento de nitrogênio com os níveis de compostos nitrogenados nas plantas.

Cataneo (1989) também observou que a suplementação de nitrogênio ocasionou incremento de aminoácidos totais tanto em folha quanto em raízes de feijoeiro.

Não houve diferença da atividade da GST entre as plantas submetidas aos tratamentos controle e aquelas com excesso de $\mathrm{N}$ (TN) e Cu

Tabela 1 - Matéria seca e área foliar em plantas de aguapé submetidas a excesso de nutrientes, em duas épocas de coleta. Botucatu-SP, 2002

\begin{tabular}{|c|c|c|c|c|c|c|}
\hline \multirow{2}{*}{\multicolumn{2}{|c|}{ Tratamento }} & \multicolumn{4}{|c|}{ Matéria seca $(\mathrm{g})$} & \multirow{2}{*}{$\begin{array}{l}\text { Área Foliar } \\
\qquad\left(\mathrm{dm}^{2}\right)\end{array}$} \\
\hline & & Folhas & Raízes & Pecíolos & Total & \\
\hline $\begin{array}{l}\text { Primeira } \\
\text { coleta } \\
(28 \mathrm{DAT})\end{array}$ & $\begin{array}{l}\text { Controle } \\
\mathrm{P} \quad\left(64 \mathrm{mg} \mathrm{L}^{-1}\right) \\
\mathrm{N}\left(420 \mathrm{mg} \mathrm{L}^{-1}\right) \\
\mathrm{Cu} \mathrm{I}\left(0,16 \mathrm{mg} \mathrm{L}^{-1}\right) \\
\mathrm{Cu} \mathrm{II}\left(0,12 \mathrm{mgL}^{-1}\right)\end{array}$ & $\begin{array}{l}2,5300 \mathrm{a} \\
2,7400 \mathrm{a} \\
2,3375 \mathrm{a} \\
2,3250 \mathrm{a} \\
2,2950 \mathrm{a}\end{array}$ & $\begin{array}{l}2,6500 \mathrm{a} \\
2,3225 \mathrm{a} \\
1,8450 \mathrm{a} \\
1,9225 \mathrm{a} \\
1,9575 \mathrm{a}\end{array}$ & $\begin{array}{l}3,6050 \mathrm{a} \\
3,4750 \mathrm{a} \\
3,2025 \mathrm{a} \\
2,9700 \mathrm{a} \\
3,0175 \mathrm{a}\end{array}$ & $\begin{array}{l}8,785 \mathrm{a} \\
8,538 \mathrm{a} \\
7,385 \mathrm{a} \\
7,218 \mathrm{a} \\
7,270 \mathrm{a}\end{array}$ & $\begin{array}{c}4694,2 \mathrm{ab} \\
5585,3 \mathrm{a} \\
3904,4 \mathrm{~b} \\
4674,5 \mathrm{ab} \\
4703,2 \mathrm{ab}\end{array}$ \\
\hline $\mathrm{F}$ & & $0,76^{*}$ & $1,22 *$ & $0,58 *$ & $0,92 *$ & $1,97 *$ \\
\hline $\mathrm{CV}$ & & 17,71 & 38,78 & 22,43 & 30,17 & 18,00 \\
\hline $\begin{array}{c}\text { Segunda } \\
\text { coleta } \\
(42 \text { DAT })\end{array}$ & $\begin{array}{l}\text { Controle } \\
\mathrm{P} \quad\left(64 \mathrm{mg} \mathrm{L}^{-1}\right) \\
\mathrm{N}\left(420 \mathrm{mg} \mathrm{L}^{-1}\right) \\
\mathrm{Cu} \mathrm{I}\left(0,16 \mathrm{mg} \mathrm{L}^{-1}\right) \\
\mathrm{Cu} \mathrm{II}\left(0,12 \mathrm{mg} \mathrm{L}^{-1}\right)\end{array}$ & $\begin{array}{r}6,2950 \mathrm{a} \\
6,5750 \mathrm{a} \\
4,2725 \mathrm{~b} \\
6,6350 \mathrm{a} \\
5,7400 \mathrm{ab}\end{array}$ & $\begin{array}{l}4,8525 \mathrm{a} \\
5,6325 \mathrm{a} \\
3,7875 \mathrm{a} \\
4,7175 \mathrm{a} \\
3,6975 \mathrm{a}\end{array}$ & $\begin{array}{c}10,9600 \mathrm{a} \\
11,1600 \mathrm{a} \\
6,3600 \mathrm{a} \\
10,7100 \mathrm{a} \\
9,1600 \mathrm{a}\end{array}$ & $\begin{array}{c}22,1100 \mathrm{ab} \\
23,3600 \mathrm{a} \\
16,4500 \mathrm{~b} \\
22,0700 \mathrm{ab} \\
18,5900 \mathrm{ab}\end{array}$ & $\begin{array}{l}15533,0 \mathrm{a} \\
16495,0 \mathrm{a} \\
8482,0 \mathrm{~b} \\
17221,0 \mathrm{a} \\
16501,0 \mathrm{a}\end{array}$ \\
\hline $\mathrm{F}$ & & $4,88 \mathrm{~ns}$ & $2,48 \mathrm{~ns}$ & $1,79 *$ & $2,70 \mathrm{~ns}$ & $12,81 \mathrm{~ns}$ \\
\hline $\mathrm{CV}$ & & 15,00 & 22,58 & 18,24 & 17,12 & 13,58 \\
\hline
\end{tabular}

* Significativo a 5\% (P>0,05); ns: não-significativo. Médias seguidas de mesma letra na coluna não diferem estatisticamente pelo teste de Tukey $(\alpha 0,05)$. DAT $=$ dias após o transplante para a solução nutritiva. 
(TCu I e TCu II) na primeira época de coleta, ao passo que o excesso de $\mathrm{P}$ (TP) causou diminuição da atividade desta enzima (Figura 2). O tratamento com $\mathrm{Cu}$ (TCu-II) causou aumento da atividade da GST na segunda coleta.

Verificou-se aumento de aproximadamente $100 \%$ na atividade da SOD nas plantas avaliadas na primeira coleta, quando cultivadas com Cu (TCu I). Na segunda coleta, as plantas submetidas ao excesso de $\mathrm{P}$ (TP) e $\mathrm{Cu}$ (nas duas concentrações) também apresentaram aumento da atividade da SOD (Figura 2).

Metais pesados, como o cobre, induzem a formação de espécies reativas de oxigênio, entre elas o radical superóxido $\left(\mathrm{O}_{2}{ }^{-}\right)$, levando ao estresse oxidativo nas plantas (Marrs, 1996). No presente estudo, o cobre (TCu II) pode ter causado estresse nas plantas de aguapé, uma vez que houve aumento da atividade da GST nessas condições, como uma tentativa de desintoxicação das plantas. Observando os resultados, pode-se verificar que a resposta da GST à presença deste elemento na planta de aguapé é manifestada de modo pronunciado em condições moderadas de estresse.

Segundo Rauser (1995), as plantas possuem mecanismos de manutenção de concentrações de metais entre os limites de deficiência e toxicidade, por meio da ação de proteínas denominadas fitoquelatinas, as quais impediriam a estimulação da atividade da GST. Por outro lado, na tentativa de eliminação dos radicais superóxido formados sob condições de adversidades ambientais, as plantas apresentam mecanismos de defesa, através do aumento da atividade da SOD, correlacionando-se ao aumento da tolerância ao estresse (Gupta et al., 1993; Mazhoudi et al., 1997; Scandalios, 1993; Tsang et al., 1991).

Neste estudo, o aumento da atividade da SOD sob condições de excesso de cobre indicou a geração de estresse oxidativo nas plantas de aguapé. Estes resultados estão de acordo com Rama Devi \& Prasad (1998), que, trabalhando com a planta aquática Ceratophyllum demersum, observaram aumento da atividade da SOD quando segmentos dessas plantas foram mantidos por 24 horas em solução nutritiva contendo excesso de cobre.

Na literatura não há concordância quanto aos efeitos da nutrição fosfatada no acúmulo de carboidratos não-estruturais, em folhas intactas. No presente trabalho, os aumentos de carboidratos nas raízes das plantas sob excesso de fósforo estão em concordância com trabalhos realizados com baixa disponibilidade

Tabela 2 - Valores percentuais de açúcares redutores, açúcares totais e aminoácidos totais de plantas de aguapé submetidas a excesso de nutrientes, em duas épocas de coleta. Botucatu-SP, 2002

\begin{tabular}{|c|c|c|c|c|c|c|c|}
\hline \multirow{2}{*}{\multicolumn{2}{|c|}{ Tratamento }} & \multicolumn{2}{|c|}{ Açúcares redutores $(\%)$} & \multicolumn{2}{|c|}{ Açúcares totais (\%) } & \multicolumn{2}{|c|}{ Aminoácidos totais (\%) } \\
\hline & & Folhas & Raízes & Folhas & Raízes & Folhas & Raízes \\
\hline $\begin{array}{l}\text { Primeira } \\
\text { coleta } \\
(28 \mathrm{DAT})\end{array}$ & $\begin{array}{l}\text { Controle } \\
\mathrm{P} \quad\left(64 \mathrm{mg} \mathrm{L}^{-1}\right) \\
\mathrm{N}\left(420 \mathrm{mg} \mathrm{L}^{-1}\right) \\
\mathrm{Cu} \mathrm{I}\left(0,16 \mathrm{mg} \mathrm{L}^{-1}\right) \\
\mathrm{Cu} \mathrm{II}\left(0,12 \mathrm{mg} \mathrm{L}^{-1}\right)\end{array}$ & $\begin{array}{l}0,0247 \mathrm{a} \\
0,0247 \mathrm{a} \\
0,0393 \mathrm{a} \\
0,0251 \mathrm{a} \\
0,0306 \mathrm{a}\end{array}$ & $\begin{array}{l}0,0213 \mathrm{a} \\
0,0369 \mathrm{a} \\
0,0201 \mathrm{a} \\
0,0200 \mathrm{a} \\
0,0213 \mathrm{a}\end{array}$ & $\begin{array}{l}0,0495 \mathrm{a} \\
0,0493 \mathrm{a} \\
0,0779 \mathrm{a} \\
0,0502 \mathrm{a} \\
0,0611 \mathrm{a}\end{array}$ & $\begin{array}{l}0,0427 \mathrm{a} \\
0,0738 \mathrm{a} \\
0,0401 \mathrm{a} \\
0,0400 \mathrm{a} \\
0,0426 \mathrm{a}\end{array}$ & $\begin{array}{l}0,0536 \mathrm{a} \\
0,0563 \mathrm{a} \\
0,0567 \mathrm{a} \\
0,0542 \mathrm{a} \\
0,0548 \mathrm{a}\end{array}$ & $\begin{array}{l}0,2600 \mathrm{~b} \\
0,2625 \mathrm{~b} \\
0,2707 \mathrm{a} \\
0,2608 \mathrm{~b} \\
0,2603 \mathrm{~b}\end{array}$ \\
\hline $\mathrm{F}$ & & $2,16 *$ & $0,89 *$ & $2,16^{*}$ & $0,89 *$ & $2,14 *$ & $11,57^{\mathrm{ns}}$ \\
\hline $\mathrm{CV}$ & & 29,29 & 64,56 & 29,29 & 64,53 & 3,34 & 0,99 \\
\hline $\begin{array}{c}\text { Segunda } \\
\text { coleta } \\
(42 \text { DAT })\end{array}$ & $\begin{array}{l}\text { TC } \\
\mathrm{P} \quad\left(64 \mathrm{mg} \mathrm{L}^{-1}\right) \\
\mathrm{N}\left(420 \mathrm{mg} \mathrm{L}^{-1}\right) \\
\mathrm{Cu} \mathrm{I}\left(0,16 \mathrm{mg} \mathrm{L}^{-1}\right) \\
\mathrm{Cu} \mathrm{II}\left(0,12 \mathrm{mg} \mathrm{L}^{-1}\right)\end{array}$ & $\begin{array}{l}0,0412 \mathrm{a} \\
0,0296 \mathrm{a} \\
0,0335 \mathrm{a} \\
0,0278 \mathrm{a} \\
0,0279 \mathrm{a}\end{array}$ & $\begin{array}{l}0,0230 \mathrm{a} \\
0,0212 \mathrm{a} \\
0,0313 \mathrm{a} \\
0,0219 \mathrm{a} \\
0,0246 \mathrm{a}\end{array}$ & $\begin{array}{l}0,0823 \mathrm{a} \\
0,0592 \mathrm{a} \\
0,0670 \mathrm{a} \\
0,0556 \mathrm{a} \\
0,0559 \mathrm{a}\end{array}$ & $\begin{array}{l}0,0459 \mathrm{a} \\
0,0424 \mathrm{a} \\
0,0626 \mathrm{a} \\
0,0437 \mathrm{a} \\
0,0491 \mathrm{a}\end{array}$ & $\begin{array}{l}0,2646 \mathrm{a} \\
0,2621 \mathrm{a} \\
0,2627 \mathrm{a} \\
0,2624 \mathrm{a} \\
0,2619 \mathrm{a}\end{array}$ & $\begin{array}{c}0,2599 \mathrm{~b} \\
0,2605 \mathrm{~b} \\
0,2687 \mathrm{a} \\
0,2600 \mathrm{~b} \\
0,2620 \mathrm{ab}\end{array}$ \\
\hline $\mathrm{F}$ & & $1,35^{*}$ & $1,83^{*}$ & $1,34 *$ & $1,84^{*}$ & $2,17 *$ & $4,58 *$ \\
\hline $\mathrm{CV}$ & & 30,23 & 24,67 & 30,28 & 24,68 & 0,55 & 1,32 \\
\hline
\end{tabular}

* Significativo a 5\% ( $>0.05)$; ns: não-significativo. Médias seguidas de mesma letra na coluna não diferem estatisticamente pelo teste de Tukey $(\alpha 0,05)$. DAT $=$ dias após o transplante para a solução nutritiva. 
deste elemento, ocorrendo redução na produção de fotoassimilados em alfafa (Vance et al., 1979) e diminuição da taxa fotossintética em soja (Qiu \& Israel, 1992).

Os resultados apresentados sugerem que, dos nutrientes em excesso avaliados, o cobre foi o maior indutor de estresse, acarretando aumentos da atividade da GST e SOD, que atuariam na desintoxicação de cobre em plantas de aguapé. Verificou-se que todos os tratamentos submetidos a niveis excessivos de nutrientes causaram alterações no desenvolvimento das plantas de aguapé.
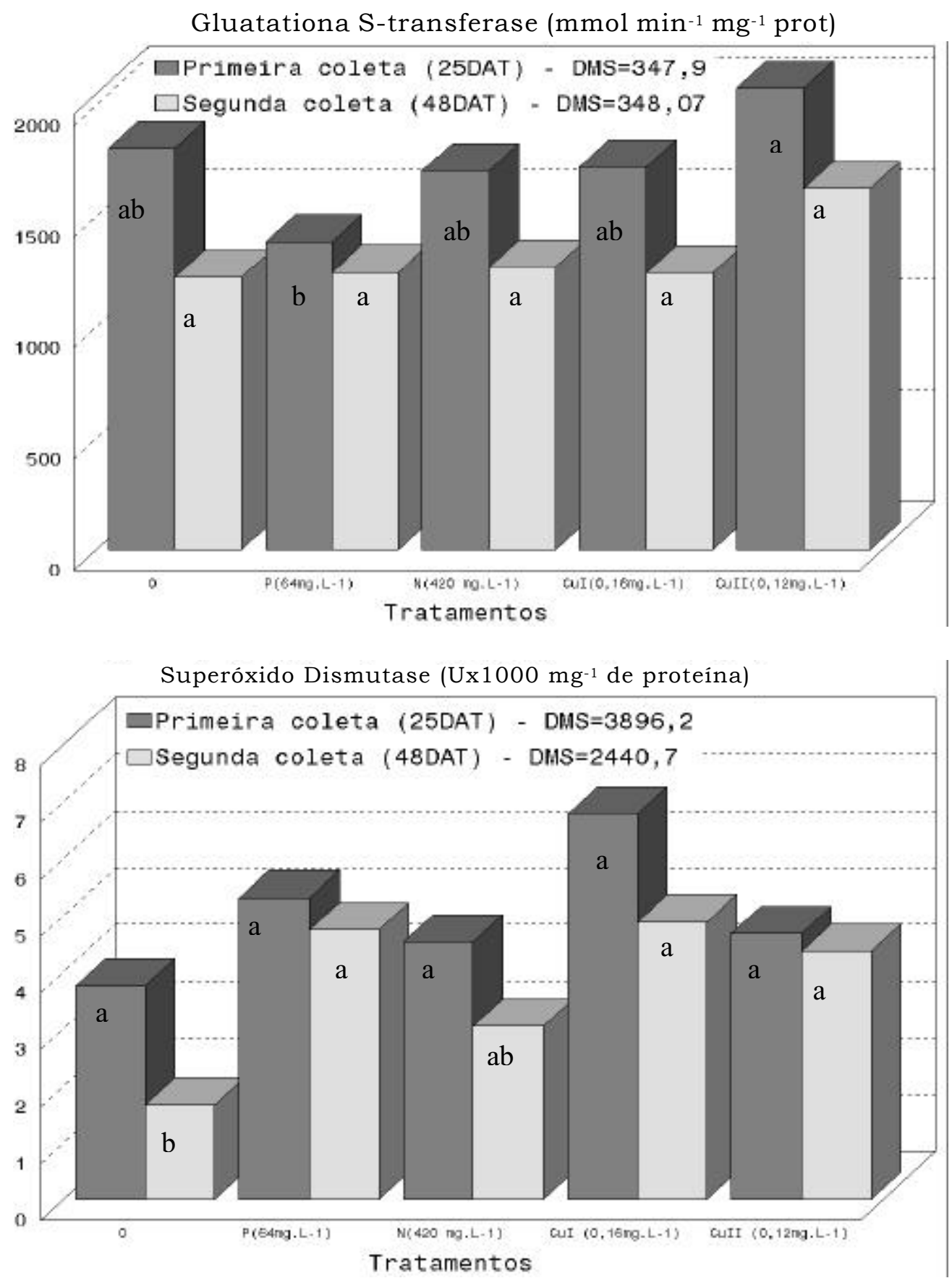

Figura 2 - Atividade de glutationa S-transferase (GST) e superóxido dismutase (SOD) em plantas de aguapé submetidas a excesso de nutrientes, em duas épocas de coleta. Botucatu-SP, 2002. 


\section{LITERATURA CITADA}

AUST, S. D.; MAREHOUSE, L. A.; THOMAS, C. E. Role of metals in oxygen radical reactions. J. Free Radic. Biol. Med., v. 1, p. 3-25, 1989.

BENINCASA, M. M. P. Análise de crescimento de plantas: noções básicas. Jaboticabal: FUNEP, 1988. 42 p.

BILANG, J. et al. A soluble auxin-binding protein from Hyoscyamus muticus is a glutathione S-transferase. Plant Physiol., v. 102, p. 29-34, 1993.

BUCHANAN, B. B.; GRUISSEM, W.; JONES, R. L. Biochemistry \& molecular biology of plants. 3.ed. Rockville: American Society of Plant, 2001. 1367 p.

CATANEO A C. Efeitos de fontes de nitrogênio (N-uréia e N-nítrico) na atividade de urease (EC 3.5.1.5), nos níveis de compostos nitrogenados e de carboidratos em feijoeiro (Phaseolus vulgaris L.) cultivar carioca, cultivado em solução nutritiva. 1989. 96 f. Dissertação (Mestrado em Ciências Biológicas) - Universidade Estadual Paulista, Botucatu, 1989.

COLEMAN, J. O. D.; RANDALL, R.; BLAKE-KALFF, M. M. A. Detoxification of xenobiotics in plant cells by glutathione conjugation and vacuolar compartmentalization: a fluorescent assay using monochlorobimane. Plant, Cell Environ., v. 20, p. 449-460, 1997.

CORRÊA, M. R.; VELINI, E. D.; ARRUDA, D. P. Teores de metais na biomassa de Egeria densa, Egeria najas e Ceratophyllum demersum. Planta Daninha, v. 20, p. 45-49, 2002.

DE VOS, C. H. R.; VONK, M. J.; SCHAT, H. Glutathione depletion due to copper induced phytochelatin synthesis causes oxidative stress in Silene cucubalus. Plant Physiol., v. 98, p. 853-858, 1992.

DUBOIS, M. et al. Colorimetric method for determination of sugars and related substances. Anal. Chem., v. 28, p. 350-356, 1956.

FRIDOVICH, I. Biological effects of the superoxide radical. Arch. Biochem. Biophys., v. 247, p. 1-11, 1986.

GIANNOPOLITIS, C. N.; RIES, S. K. Superoxide dismutases: I. Occurrence in higher plants. Plant Physiol., v. 59, p. 309-314, 1977.

GUPTA, A. A. et al. Overexpression of superoxide dismutase protects plants from oxidative stress. Plant Physiol., v. 103, p. 1067-1073, 1993.

HOAGLAND D. R.; ARNON D. I. The water-culture method for growing plants without soil. California Agricultural Experiment Station, 1950 (Circulation, 347), 1950.
KABAT, E. A.; MAYER, M. M. Experimental immunochemistry. 2.ed. Spring Field; C.C. Thomas, 1967. p. $560-563$.

LAM, H. M. et al. The molecular-genetics of nitrogen assimilation into amino acids in higher plants. Ann. Rev. Plant Physiol. Plant Mol. Biol., v. 47, p. 569-593, 1996.

LOPES-FERREIRA, C. M. O papel de uma região colonizada por mcrófitas aquáticas na depuração de efluentes domésticos na lagoa imboacica (Macaé-RJ). 1995. 96 f. Dissertação (Mestrado em Ciências Ambientais) - Universidade Federal do Rio de Janeiro, Rio de Janeiro, 1995.

LOWRY, O. H. et al. Protein measurement with Folinphenol reagent. J. Biol. Chem., v. 193, p. 265-275, 1951.

MACDONALD, H.; JONES, A. M.; KING, P. J.

Photoaffinity labeling of soluble auxin-binding proteins. J. Biol. Chem., v.266, p.7393-73999, 1991.

MARCONDES, D. A. S., TANAKA, R. H. Plantas aquáticas nos reservatórios das usinas hidrelétricas da CESP. In: CONGRESSO BRASILEIRO DA CIÊNCIA DAS PLANTAS DANINHAS, 21., 1997, Caxambu. Workshop de Plantas Aquáticas... Caxambu: Sociedade Brasileira da Ciência das Plantas Daninhas, 1997. p. 2-4.

MARRS, K. A. The functions and regulation of glutathione S-transferase in plants. Ann. Rev. Plant Physiol. Plant Mol. Biol., v. 47, p. 127-158, 1996.

MARSCHNER, H. Mineral nutrition of higher plants. 2.ed. San Diego: Academic Press, 1995. 902 p.

MAZHOUDI, S. et al. Response of antioxidant enzymes to excess copper in tomato (Lycopersicon esculentum, Mill.). Plant Sci., v. 127, p. 129-137, 1997.

MORAES, A. R. Estimativa de estoque de elementos químicos em macrófitas aquáticas do reservatório de Salto Grande (Americana-SP). 1999. 94 f. Dissertação (Mestrado em Ciências da Engenharia Ambiental) Universidade de São Paulo, São Carlos, 1999.

NELSON, D. L.; COX, M. M. Lehninger: principles of biochemistry. 3.ed. New York: Worth Publischers, 2000. $1152 \mathrm{p}$.

NELSON, N. A. A photometric adaptation of the SOMOGY method for the determination of glucose. J. Biol. Chem., v. 153, p. 375-380, 1944.

NEVES, T.; FOLONI, L. L.; PITELLI, R. A. Controle químico do aguapé (Eichhornia crassipes). Planta Daninha, v. 20, p. 89-97, 2002. 
QIU, J.; ISRAEL, D. W. Diurnal starch accumulation and utilization in phosphorus-deficient soybean plant. Plant Physiol., v. 98, p. 316-323, 1992.

RAMA DEVI, S.; PRASAD, M. N. V. Copper toxicity in Ceratophyllum demersum L. (Coontail), a free floating macrophyte: Response of antioxidant enzymes and antioxidants. Plant Sci., v. 138, p. 157-165, 1998.

RAUSER, W. E. Phytochelatins and related peptides (structure, biosynthesis and function). Plant Physiol., v. 109, p. 1141-1149, 1995.

SCANDALIOS, J. G. Oxygen stress and superoxide dismutases. Plant Physiol., v. 101, p. 7-12, 1993.
SIES, H. Strategies of antioxidant defense. Eur. J. Biochem., v. 215, p. 213-219, 1993.

TSANG, E. W. T. et al. Differential regulation of superoxide dismutases in plants exposed to environmental stress. Plant Cell, v. 3, p. 783-792, 1991.

VANCE, C. P. Nitrogen fixation, nodule development and vegetative regrowth of alfalfa (Medicago sativa $\mathrm{L}$.) following harvest. Plant Physiol., v. 64, p. 1-8, 1979.

WU, J. Glutathione S-transferase activity in unsafened and fenclorim-safened rice. Pest. Biochem. Physiol., v. 54, p. 220-229, 1996. 